International Journal of Engineering \&Technology, $7(1.8)(2018) 86-91$
SPC
International Journal of Engineering \& Technology
Website www.sciencepubco.com/index.php/IJET
Research paper

\title{
Modeling and analysis of a hybrid boost DC-DC converter for distributed generation
}

\author{
M. V. Sudarsan ${ }^{1 *}$, Ch. Saibabu ${ }^{2}$, S. Satyanarayana ${ }^{3}$ \\ ${ }^{1}$ Associate Professor in EEE, Vignan's Lara Institute of Technology and Science, Vadlamudi, Andhra Pradesh, India \\ ${ }^{2}$ Professor in EEE, University College of Engineering, JNTUK, Kakinada, Andhra Pradesh, India \\ ${ }^{3}$ Professor in EEE, Raghu Engineering College, Visakhapatnam, Andhra Pradesh, India \\ *Corresponding author E-mail: mvsudarsan.eee@gmail.com
}

\begin{abstract}
As the power generating stations are located very far from the load centers, there is a necessity to transmit the power through the long transmission lines. The transmission efficiency and voltage profile are poor, due to the large amount of line losses and voltage drop. Thus to improve its performance, the generation of the power has to be done at the vicinity of load centers and is possible through the distributed generation (DG). The DG system consists of a boost converter which increases the dc input voltage obtained from an array of PV cells arranged on the solar panels. In this paper, the hybrid boost converter which is a high gain step-up dc-dc converter is modeled and analyzed for DG applications. The gain of this hybrid converter is D (duty ratio) times more than the normal boost converter and posses the advantages like less ripple current and high efficiency. Also the dynamic performance of the converters is compared in both open and closed loops from the simulation work carried out in MATLAB / Simulink environment.
\end{abstract}

Keywords: DC-DC Converter; Distributed Generation; PV System; Renewable energy sources.

\section{Introduction}

The power generated at the power plants is transferred through transmission lines to the load centers. In the process of this transmission of electrical energy, the power loss and the voltage drop takes place in the line and are considered as an important factors for optimal utilization of energy. To overcome these drawbacks, now-a-days so many researchers have been carried out their research on distributed generation (DG) [1-3]. In DG system, the power is generated at load center itself. This would minimize the transmission line cost, power loss and also improves the voltage profile. The installation of DG system must maximize the benefits and at the same time it should not increase the complexity of existing power system.

The DG is possible by using renewable energy sources (RES) [45]. These renewable energy sources cause no pollution and it has global accessibility. Also, the world is more relying on the RES rather than the conventional energy sources. Because, the conventional fossil fuel sources may diminish with time. Solar energy, wind energy, fuel cell, bio mass, tidal energy etc. falls under the renewable energy sources. Out of all these sources, solar energy is the most commonly used source because of its flexibility and availability. The output voltage of photo voltaic (PV) [6-8] system is DC and is of very less value. Therefore, utilities which are connecting to renewable energy source generation face challenges in ensuring voltage regulation, stability and power quality. To meet these challenges, the DC-DC converters [9-11] are introduced in between the utility and generation. DC-DC converters plays vital role in maintaining the better voltage regulation with reliability. DC-DC converters steps up the low voltage output of PV system. These DC-DC converters are of two types namely, isolated type and non-isolated type where the coupled inductors are used in both. The primary function of the DC-DC converter is to step up the voltage level with high voltage gain based on the duty ratio of the converter. In conventional existing converters, the voltage gain is increased with increasing the duty ratio. In this paper, the hybrid boost converter which is a high gain step-up dc-dc converter is modeled and analyzed for DG applications. The gain of this hybrid converter is $\mathrm{D}$ (duty ratio) times more than the normal boost converter and posses the advantages like less ripple current and high efficiency. Also the dynamic performance of the converters is compared in both open and closed loops from the simulation work carried out in MATLAB / Simulink environment.

\section{Boost converter}

The conventional boost converter is shown in Fig.1. In this, the boosting operation is carried out by the inductor connected to input side. The switch ' $S$ ' is connected in parallel to the output capacitor. The power to the load is supplied by the output capacitor in the absence of source i.e during the on state of the switch and through the inductor stored energy along with the input source during the off state of the switch. Here, the diode is connected to avoid discharging of capacitor through switch when switch ' $\mathrm{S}$ ' is closed. 


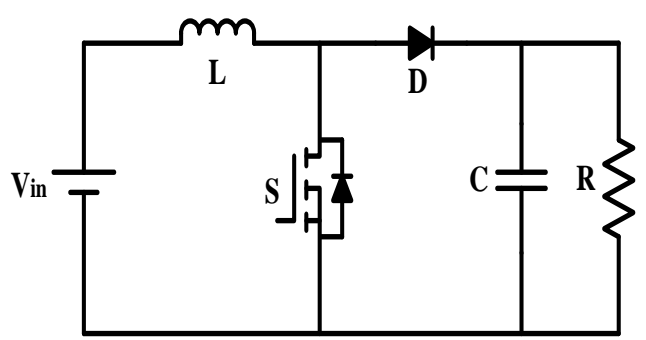

Fig. 1: Boost Converter.

The operation of boost converter is explained in two modes with switch ON and OFF states. When switch S is ON then, the source is short circuited through inductor and turned on switch. The converter with switch in ON state is shown in Fig.2 (a). During this period, the inductor gets charged by the supply voltage to the source voltage $V_{\text {in }}$. Meanwhile power to the load is supplied by the output capacitor C. Fig.2 (b) shows the boost converter with switch in OFF state, during this period the stored energy of the inductor is discharged to load along with the source.

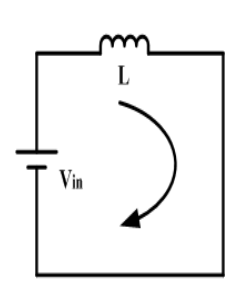

(a)

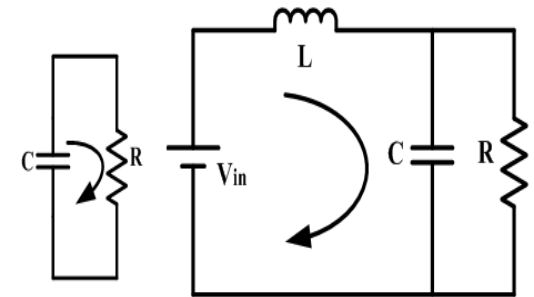

(b)
Fig. 2: Boost Converter Operation (A) Switch 'On' (B) Switch 'Off'.

Therefore, voltage across load is increased and is known as boosting operation. The output capacitor ' $\mathrm{C}$ ' charges during switch $\mathrm{OFF}$ condition. The Performance of boost converter is characterized by the voltage gain and depends on the duty ratio $\mathrm{D}$. The duty ratio is defined as the ratio of ON time of the switch to the total time of a switching cycle. The voltage gain of the conventional boost converter is given in eq. (1) with the analysis of inductor voltage shown in Fig.3.

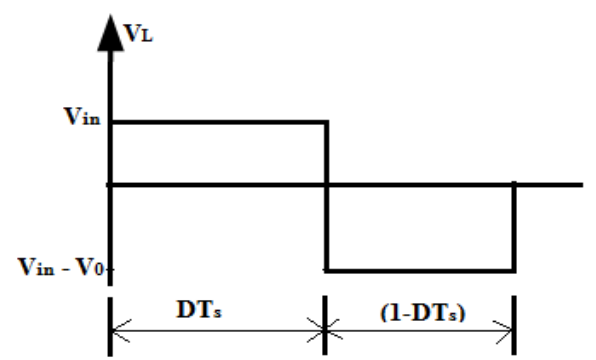

Fig. 3: Inductor Voltage Waveform of Boost Converter.

The average voltage of the inductor is made to zero, and then the gain of the converter is

$$
\frac{\mathrm{V}_{\text {in }} \mathrm{DT} \mathrm{T}_{\mathrm{s}}+\left(\mathrm{V}_{\mathrm{in}}-\mathrm{V}_{\mathrm{o}}\right)(1-\mathrm{D}) \mathrm{T}_{\mathrm{s}}}{\mathrm{T}_{\mathrm{s}}}=0
$$

$$
\mathrm{V}_{\text {guin }}=\frac{\mathrm{V}_{0}}{\mathrm{~V}_{\text {in }}}=\frac{1}{1-\mathrm{D}}
$$

Therefore in the conventional boost converter the voltage gain varies from $V_{\text {in }}$ to infinity with respect to the variation of the duty ratio from 0 to 1 respectively.

\section{Hybrid boost converter}

The circuit diagram of hybrid boost converter is shown in Fig.4. The topology of hybrid converter is similar to the existed boost converter except, it has two controlled switches $S_{1}, S_{2}$ and two boosting inductors $\mathrm{L}_{1}, \mathrm{~L}_{2}$.

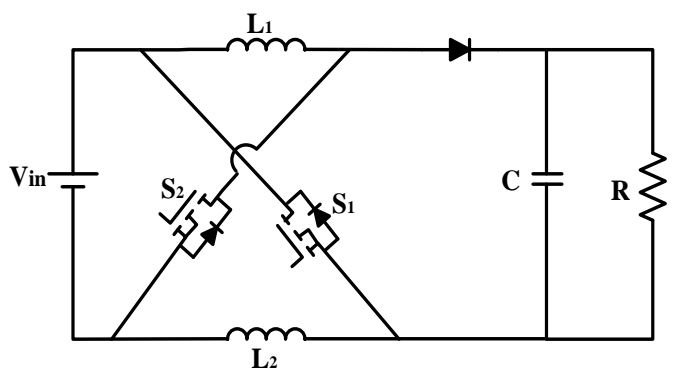

Fig. 4: Hybrid Boost Converter.

The switches and inductors are connected in the $\mathrm{Z}$ shape. Despite of increased count of components this configuration gives high voltage gain for the same duty ratio as compared to conventional boost converter.

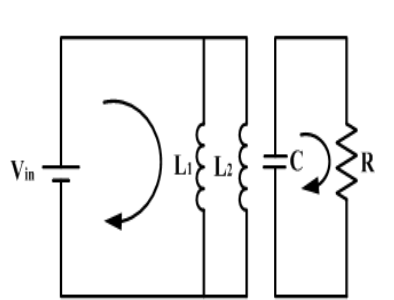

(a)

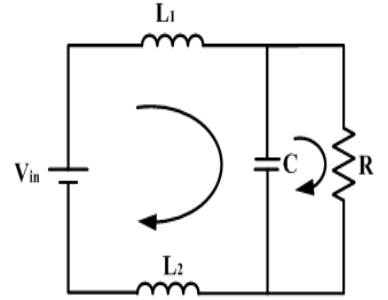

(b)
Fig. 5: Hybrid Boost Converter (A) Switches 'On' (B) Switches 'Off'.

The circuit configurations of the hybrid boost converter during switches ON and OFF condition are shown in Fig.5 (a) and (b). When both switches are in ON state, both the inductors are charged to supply voltage $V_{\text {in }}$ and the power to the load is supplied by the output capacitor. When switches are in OFF state, then the charged inductors are discharged to the load and the output capacitor gets charged. The voltage gain of the hybrid boost converter is derived by making the average voltage of the inductors to zero over a switching cycle and is shown in Fig.6.

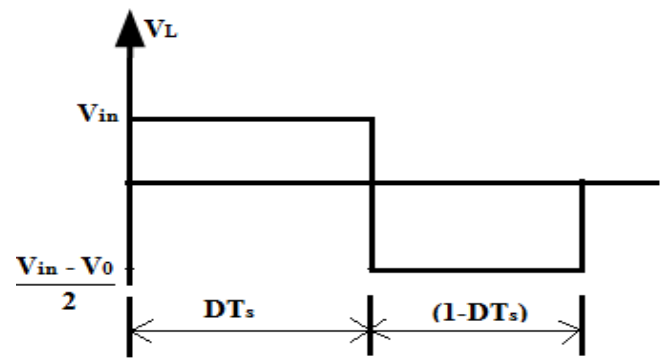

Fig. 6: Inductor Voltage Waveform of Hybrid Boost Converter.

Then the gain of the converter is

$$
\frac{\mathrm{V}_{\text {in }} \mathrm{DT}_{\mathrm{S}}+\left(\frac{\mathrm{V}_{\text {in }}-\mathrm{V}_{0}}{2}\right)(1-\mathrm{D}) \mathrm{T}_{\mathrm{S}}}{\mathrm{T}_{\mathrm{s}}}=0
$$

$\mathrm{V}_{\text {gain }}=\frac{\mathrm{V}_{0}}{\mathrm{~V}_{\text {in }}}=\frac{1+\mathrm{D}}{1-\mathrm{D}}$ 
Thus from eq. (2), the hybrid boost converter has high voltage gain when compared with the conventional boost converter.

\section{Closed loop control of converters}

Fig.7 depicts the closed loop control of conventional boost converter with PI controller. The main purpose of closed loop control is to maintain the constant output voltage even if there is a disturbance in the load.

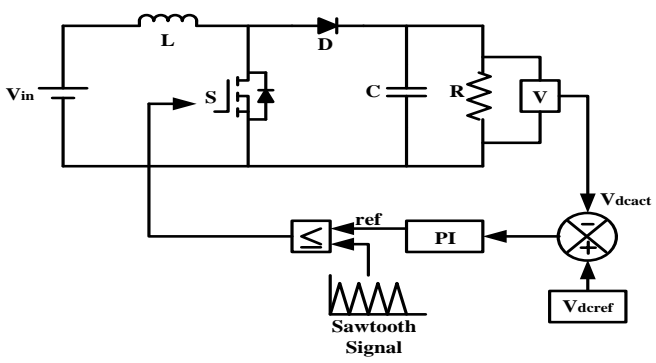

Fig. 7: PI Controlled Boost Converter.

To perform this, the output voltage $\left(\mathrm{V}_{\text {dcact }}\right)$ is compared with the desired voltage $\left(\mathrm{V}_{\text {dcref }}\right)$ and the error is applied to the proportional integral (PI) controller. The PI controller generates a reference signal proportional to the error voltage and this reference waveform is compared with the saw tooth carrier signal to generate gating pulses to the switch. This process continues until the error voltage is zero.

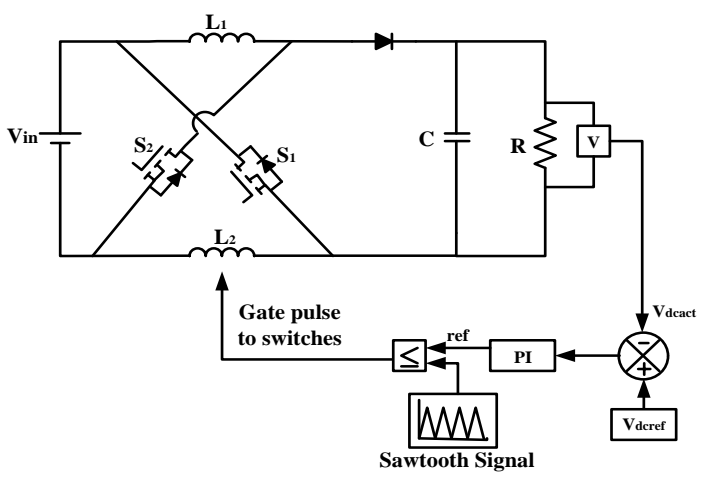

Fig. 8: Pi Controlled Hybrid Boost Converter.

Also, Fig.8 depicts the schematic diagram of the closed loop control of a hybrid boost converter with PI controller. The operation of the closed loop control is same as that of the conventional boost converter.

\section{Simulation results}

The specifications of the boost and hybrid boost converters are described in Table 1. The performance of the converters is analysed through the simulation in MATLAB / Simulink environment and these are designed to boost the voltage from $100 \mathrm{~V}$ to $400 \mathrm{~V}$ at a switching frequency of $20 \mathrm{KHz}$.

Table 1: Specifications of the Boost and Hybrid Boost Converters

\begin{tabular}{lll}
\hline \multirow{2}{*}{ Parameters } & $\begin{array}{c}\text { Specifications } \\
\text { Boost Converter }\end{array}$ & Hybrid Boost Converter \\
\hline DC Input Voltage $\left(\mathrm{V}_{\text {in }}\right)$ & $100 \mathrm{~V}$ & $100 \mathrm{~V}$ \\
Power rating $\left(\mathrm{P}_{0}\right)$ & $10 \mathrm{KW}$ & $10 \mathrm{KW}$ \\
Boosting Inductor $\left(\mathrm{L}_{1}, \mathrm{~L}_{2}\right)$ & $0.75 \mathrm{mH}$ & $\mathrm{L}_{1}=\mathrm{L}_{2}=0.6 \mathrm{mH}$ \\
Switching frequency $\left(\mathrm{f}_{\mathrm{s}}\right)$ & $20 \mathrm{~K} \mathrm{~Hz}$ & $20 \mathrm{KHz}$ \\
Output Capacitor $(\mathrm{C})$ & $120 \mu \mathrm{F}$ & $96 \mu \mathrm{F}$ \\
Output voltage $\left(\mathrm{V}_{\text {out }}\right)$ & $400 \mathrm{~V}$ & $400 \mathrm{~V}$ \\
\hline
\end{tabular}

a) Simulink models of boost and hybrid boost converter

Fig.9 shows the Simulink model of the boost converter used to step up the DC voltage from $100 \mathrm{~V}$ to $400 \mathrm{~V}$ at a switching frequency of $20 \mathrm{KHz}$.

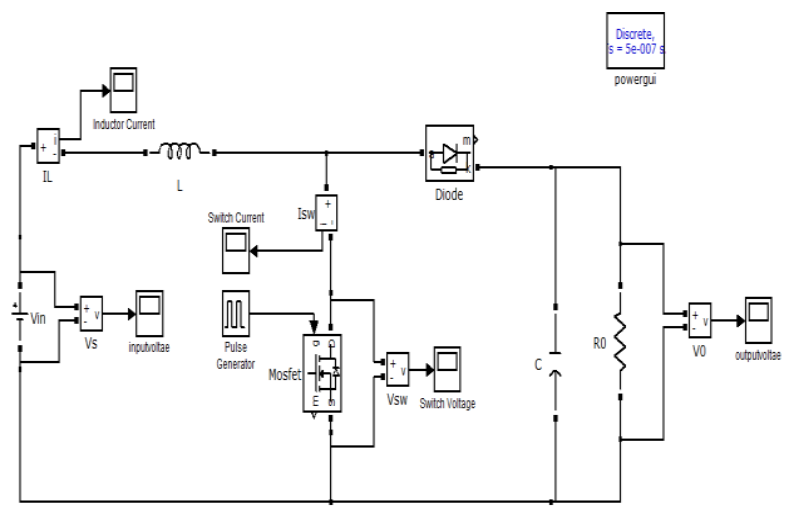

Fig. 9: Simulink Model of Boost Converter.

The output voltage and the current of the boost converter operated for a duty ratio of 0.75 is shown in Fig. 10 and settles to a steady state values of $400 \mathrm{~V}$ and $25 \mathrm{~A}$ respectively at $0.018 \mathrm{sec}$, with a ripple content of $2 \%$ and $2.4 \%$. Fig. 11 shows the boosting inductor voltage and current waveforms and the inductor current settles at $100 \mathrm{~A}$ with a ripple current of $4 \%$. Also, the Fig's 12 and 13 shows the voltages and currents of the switch and diode of the boost converter.
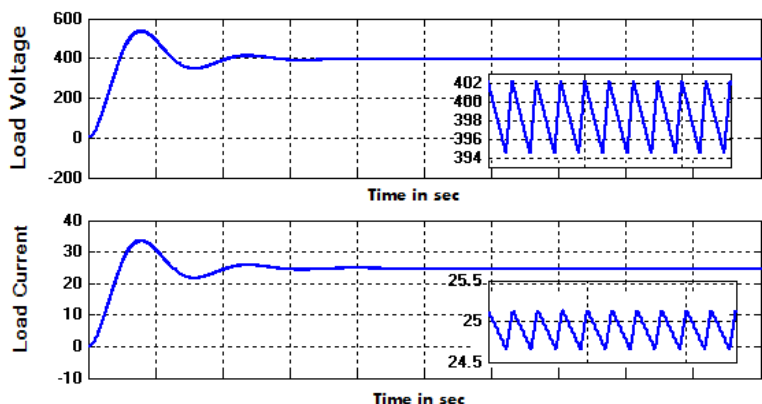

Fig. 10: Output Voltage and Current of Boost Converter.
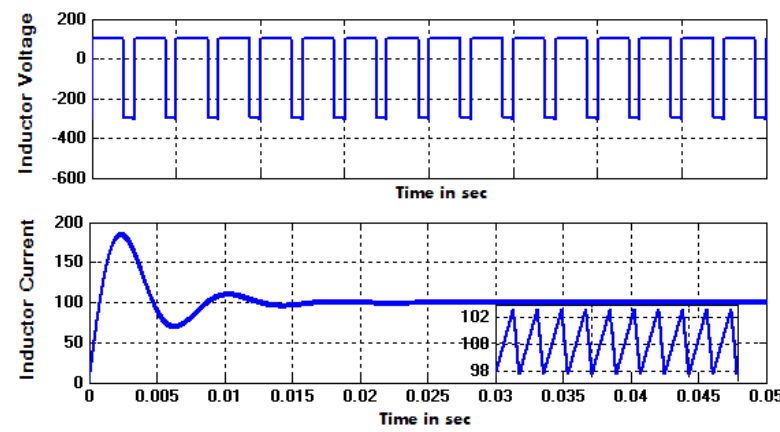

Fig. 11: Inductor Voltage and Current of Boost Converter.
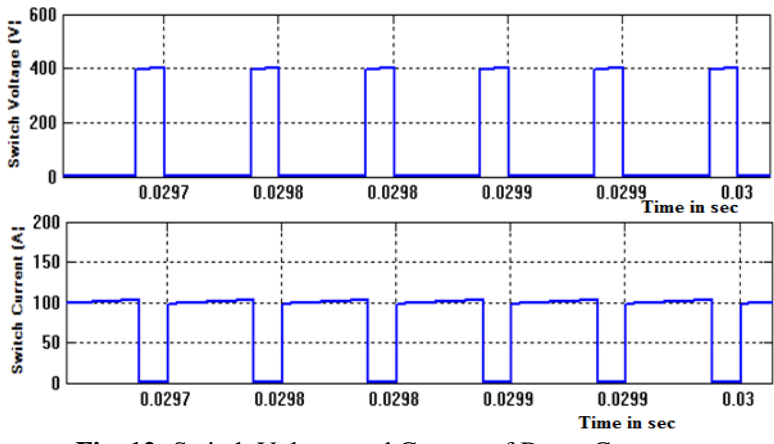

Fig. 12: Switch Voltage and Current of Boost Converter. 

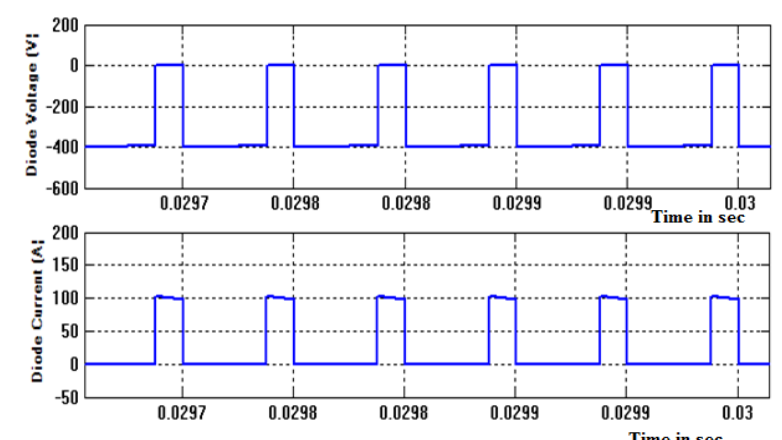

Fig. 13: Diode Voltage and Current of Boost Converter.

Fig.14 shows the Simulink model of the hybrid boost converter used to step up the DC voltage from $100 \mathrm{~V}$ to $400 \mathrm{~V}$ at a switching frequency of $20 \mathrm{KHz}$. Fig. 15 shows the input voltage of $100 \mathrm{~V}$ to the converter and boosted output voltage of $400 \mathrm{~V}$ from the converter. This boosting is done with the hybrid boost converter at a less value of duty ratio with 0.6 when compared to the conventional boost converter with a duty ratio of 0.75 . Hence, with the duty ratio of the conventional boost converter, the hybrid boost converter can boost the voltage to $700 \mathrm{~V}$. (i.e D times more than the conventional boost converter).

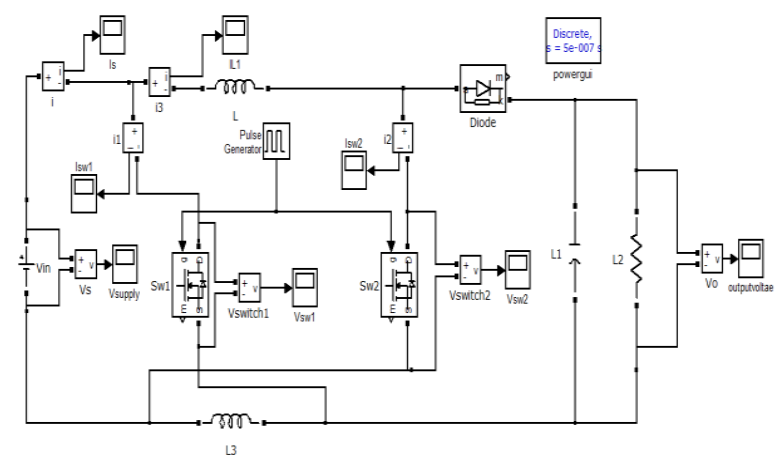

Fig. 14: Simulink Model of Hybrid Boost Converter.
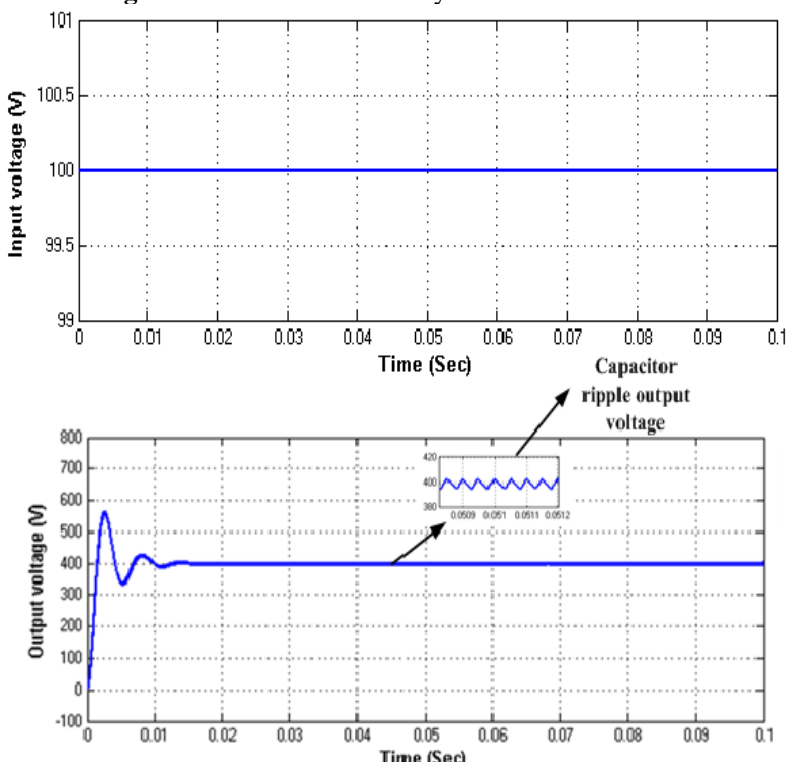

Fig. 15: Input and Output Voltages of Hybrid Boost Converter.
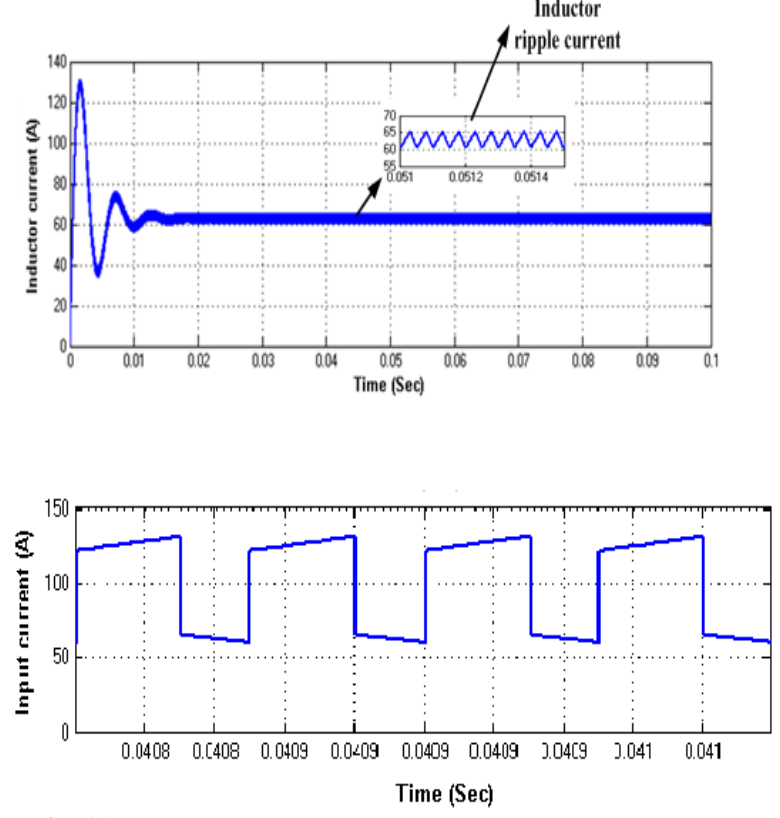

Fig. 16: Input and Inductor Currents of Hybrid Boost Converter.

The inductor and input currents of the hybrid boost converter are shown in fig. 16 with a small ripple value of $2 \%$ when compared with the conventional boost converter. The voltage and current responses of the switches connected in $\mathrm{Z}$ shape and the rectifying diode are shown in Fig. 17 (a) to (f).
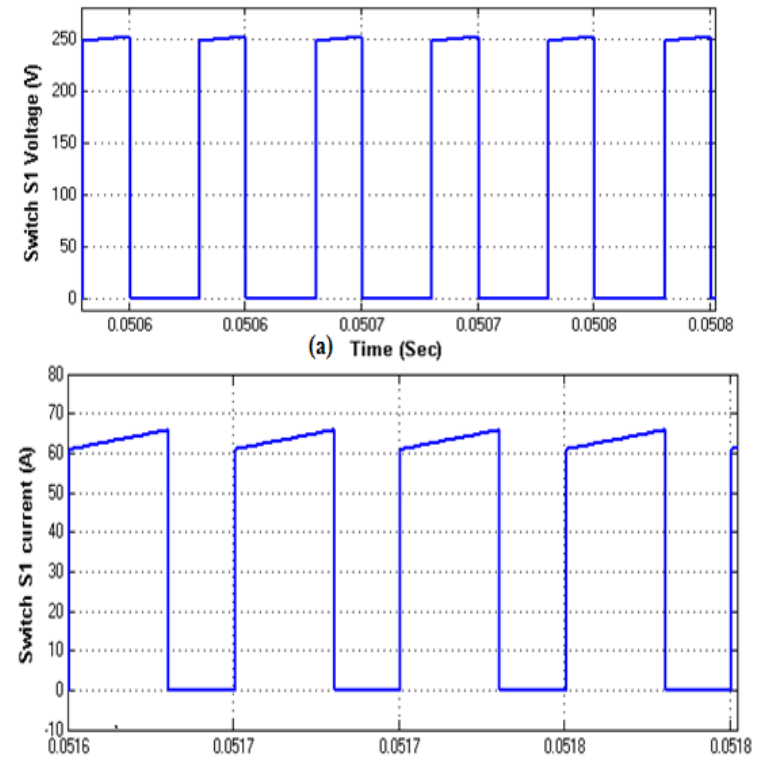

(b) Time (Sec)

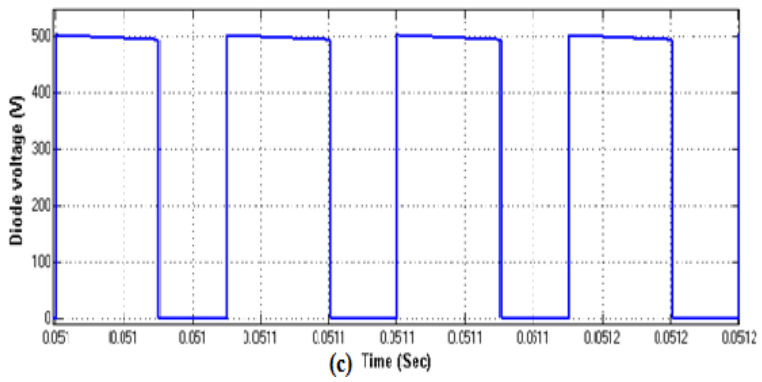




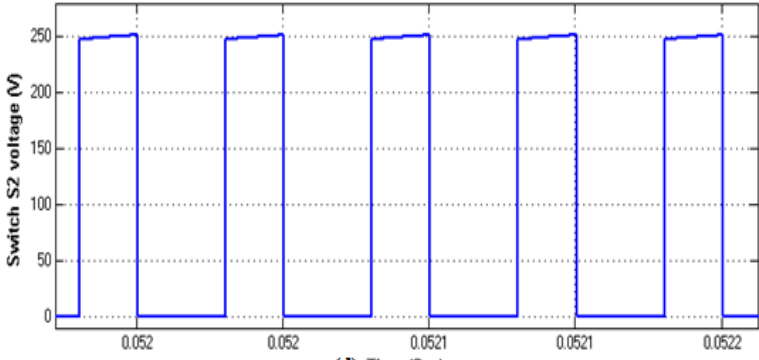

(d) Time (Sec)

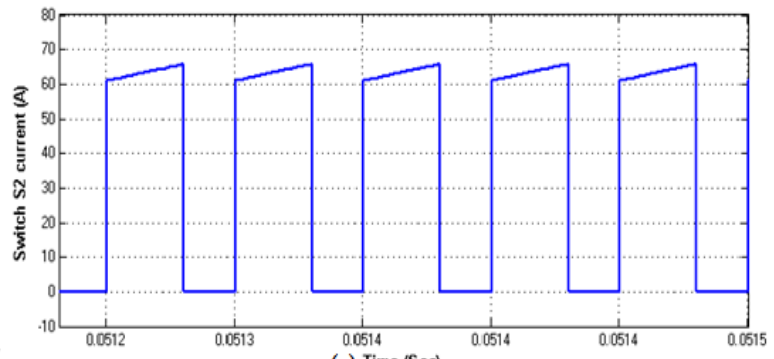

(e) Time (Sec)

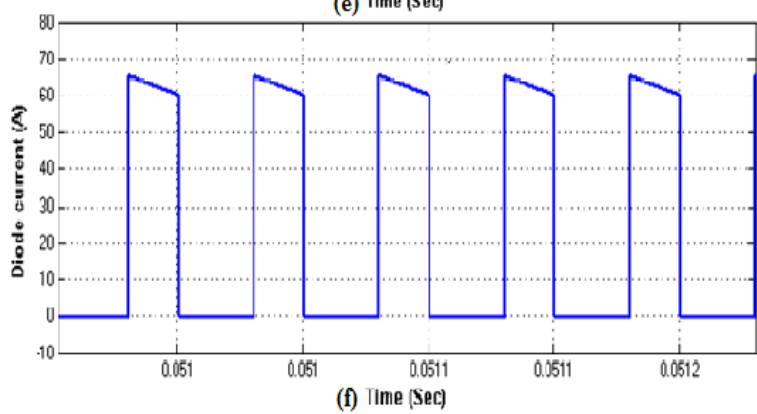

Fig. 17: Hybrid Boost Converter (A) Voltage of $S_{1}$ (B) Current of $S_{1}(C)$ Voltage of D (D) Voltage of $S_{2}(E)$ Current of $S_{2}(F)$ Current of D.

b) Simulink of boost and hybrid boost converters in closed loop control

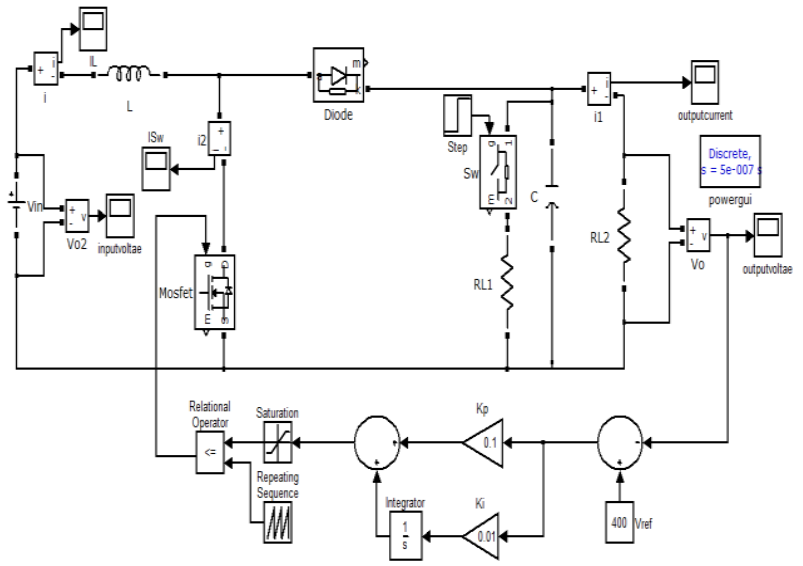

Fig. 18: Simulink of PI Controlled Boost Converter with Load Disturbance.

Fig.18 depicts the Simulink model of the boost converter in closed loop control with PI controller for maintaining the regulated voltage of $400 \mathrm{~V}$ even under the disturbance of the load. The disturbance of the load is done at $0.02 \mathrm{sec}$ with a value of load increased to twice.

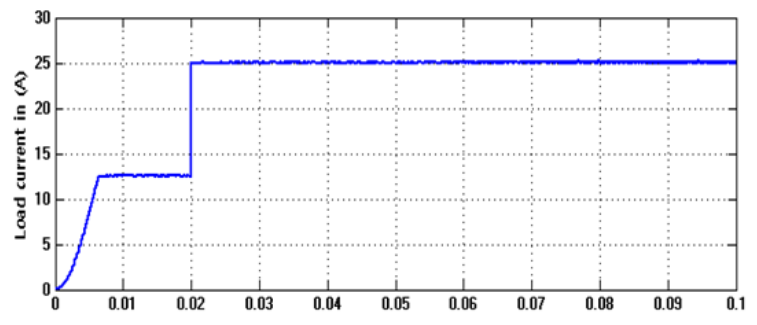

(a) Time in sec

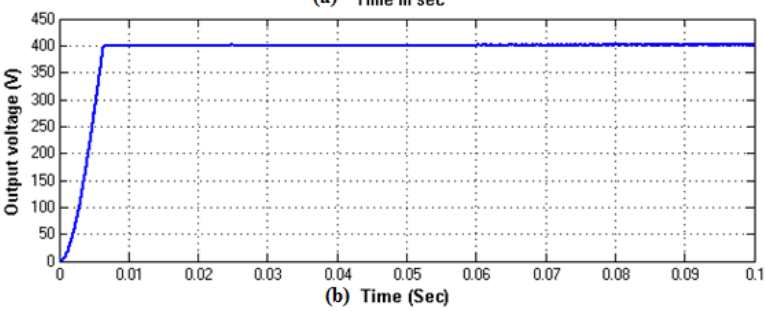

Fig. 19: PI Controlled Boost Converter (A) Load Current (B) Load Voltage.

Fig.19 (a) and (b) shows the load current and load voltage waveforms of the boost converter subjected to a load disturbance of increased twice at $0.02 \mathrm{sec}$. even under this load disturbance the converter delivers an regulated voltage of $400 \mathrm{~V}$ and a current increment from $12.5 \mathrm{~A}$ to $25 \mathrm{~A}$ at $0.02 \mathrm{sec}$.

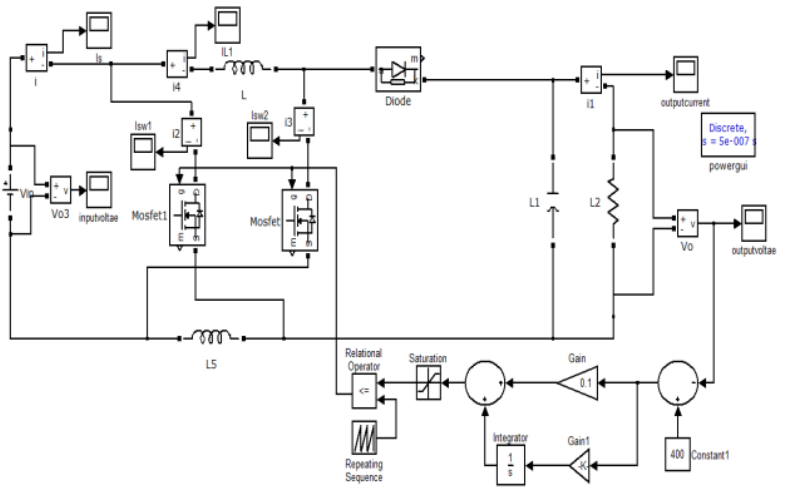

Fig. 20: Simulink of Pi Controlled Hybrid Boost Converter with Fixed Load.

Fig.20 depicts the Simulink model of the hybrid boost converter in closed loop control with PI controller for maintaining the regulated voltage of $400 \mathrm{~V}$ with fixed load.

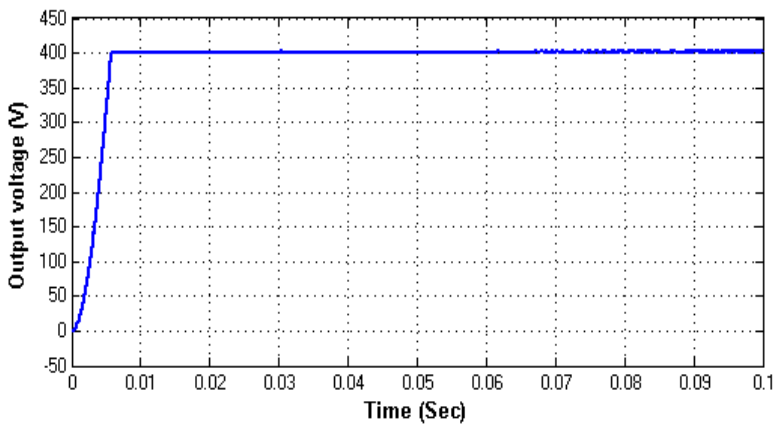

Fig. 21: Simulink of PI Controlled Hybrid Boost Converter with Fixed Load.

The hybrid boost converter in a closed loop is modeled with an input voltage of 100 volts and the converter output is 400 volts with less duty ratio than the conventional boost converter. The output voltage waveform for a fixed load are shown in Fig.21 


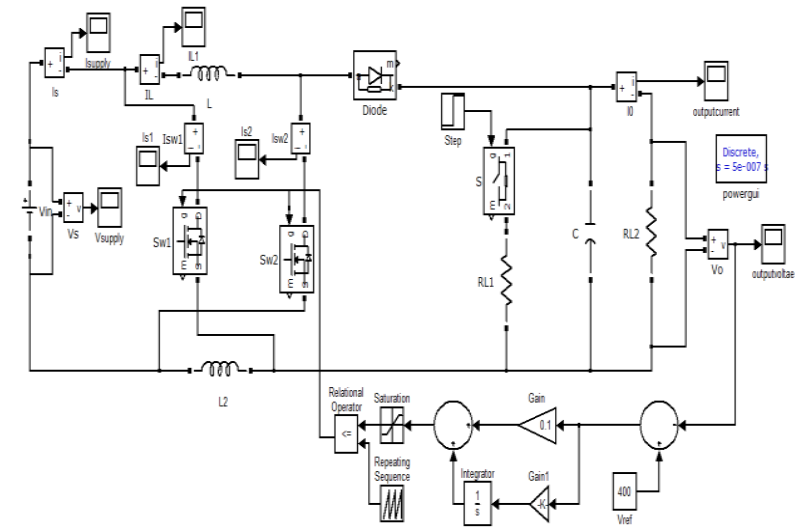

Fig. 22: Simulink Diagram of the Hybrid Boost Converter with PI Control against Load Disturbance.

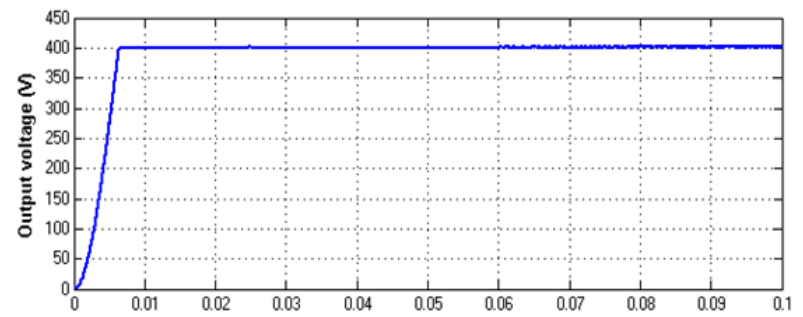

(a) Time in sec

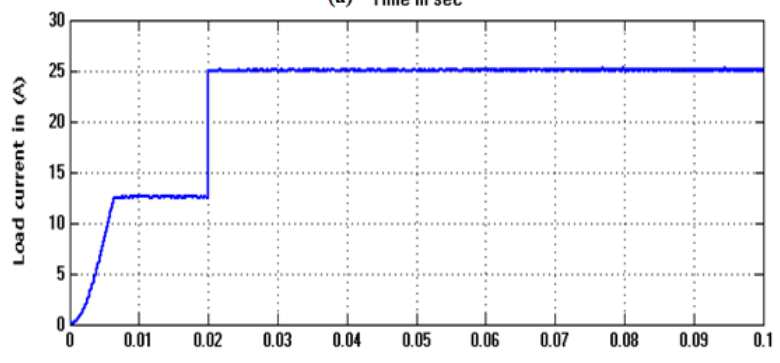

(b) Time (Sec)

Fig. 23: PI Controlled Boost Converter (A) Load Voltage (B) Load Current.

Fig.23 shows the load voltage and load current waveforms of the hybrid boost converter subjected to a load disturbance of increased twice at $0.02 \mathrm{sec}$, even under this load disturbance the converter delivers an regulated voltage of $400 \mathrm{~V}$ and a current increment from $12.5 \mathrm{~A}$ to $25 \mathrm{~A}$ at $0.02 \mathrm{sec}$

\section{Conclusion}

In this paper, the open loop and closed loop operation of conventional boost converter and hybrid boost converter is analyzed. It is observed that, the hybrid boost converter can boost up the voltage duty times more than the voltage that is boosted by the conventional boost converter for the same input voltage. Thus, to get a boosted voltage of $400 \mathrm{v}$ with an input of $100 \mathrm{~V}$, the conventional boost converter operates for a duty ratio of 0.75 , whereas the hybrid boost converter delivers the same voltage for less duty ratio of 0.6 only, therefore the switch on time reduces and the conduction losses are reduced. Even though, the number of components required for hybrid boost converter is more, the increased output voltage dominates the increased components count. Therefore, the hybrid boost converter is strongly recommended than conventional boost converter. The circuits are modeled in Matlab/Simulink software and results are analyzed.

\section{References}

[1] A, Kumar, R, Peri, U. Kundu and P, Sensarma, A high voltage gain current fed non-isolated dc-dc converter. 2016 IEEE International Conference on Power Electronics, Drives and Energy Systems (PEDES), Trivandrum, India. 2016

[2] O, N, Faqhruldin, E, F, El-Saadany, and H, H, Zeineldin. A universal islanding detection technique for distributed generation using pattern recognition" IEEE Trans. Smart Grid. 2014; 5(4):19851992. https://doi.org/10.1109/TSG.2014.2302439.

[3] A, Samui, S, R, Samantaray. Wavelet singular entropy-based islanding detection in distributed generation. IEEE Trans. Power Del. 2013; 28(1): 411-418. https://doi.org/10.1109/TPWRD.2012.2220987.

[4] R, F, Arritt, R, C, Dugan. Review of impacts of distributed generation on distribution protection. Proc.2015 IEEE Rural Electric Power Conference. $\quad$ 2015; 69-74 https://doi.org/10.1109/REPC.2015.12.

[5] A, Gandhar, A, Jindal, V, Srivastava and U, Agarwal. Renewable energy sources based power converter with voltage and load angle control. 2016 Second International Innovative Applications of Computational Intelligence on Power, Energy and Controls with their Impact on Humanity (CIPECH), Ghaziabad, India. 2016; 96100.

[6] J, M, Andújar, F, Segura and T, Domínguez. Study of a renewable energy sources-based smart grid. Requirements, targets and solutions. 2016 3rd Conference on Power Engineering and Renewable Energy (ICPERE), Yogyakarta. 2016; 45-50.

[7] S, Vyas, R, Kumar and R, Kavasseri. Statistical identification and classification of potential islanding precursors in a grid-connected Solar Photo Voltaic system. 2016 IEEE 6th International Conference on Power Systems (ICPS), New Delhi, 2016; 1-6.

[8] S, Semaoui, Hadj Arab, S, Bacha, B. Azoui. The new strategy of energy management for a photovoltaic system without extra intended for remote-housing. Sol. Energy. 2013; 94(2013): 71-85.

[9] M, Einozahy, M, Salama. Technical impacts of grid-connected photovoltaic systems on electrical networks - A review. J. Renewable Sust. Energy. 2013; 5(3).

[10] B, V, Kumar, R, K, Singh and R, Mahanty, A modified nonisolated bidirectional DC-DC converter for EV/HEV's traction drive systems. 2016 IEEE International Conference on Power Electronics, Drives and Energy Systems (PEDES), Trivandrum, India. 2016; 1-6.

[11] C, C, Lin, L, S, Yang, G, W, Wu, Study of a non-isolated bidirectional DC-DC converter. IET Power Electronics. Jan. 2013; 6(1): 30-37. 